Supporting Information for

\title{
Secondary flows, mixing, and chemical reaction analysis of droplet- based flow inside serpentine microchannels with different cross- sections
}

\author{
Erfan Ghazimirsaeed*, Masoud Madadelahi*, Mahdi Dizani*, Amir Shamloo ${ }^{\dagger}$ \\ Department of Mechanical Engineering, Sharif University of Technology \\ * These authors contributed equally to this work \\ † Corresponding Author at Department of Mechanical Engineering, Sharif University of \\ Technology, Azadi Ave., Tehran, Iran. Tel.: +98 21-66165691; Fax: 98-21-66165599; \\ email:shamloo@sharif.edu.
}

Number of pages: 16

Number of figures: 14

Number of tables: 1 
Table S1. Boundary conditions utilized in the simulations.

\begin{tabular}{|c|c|c|c|c|c|}
\hline Parameters & Inlet 1 & Inlet 2 & Inlet 3 & Outlet & Walls \\
\hline Velocity & $\mathrm{WF} \cdot \overrightarrow{\mathrm{u}}_{3}$ & $\mathrm{WF} \cdot \overrightarrow{\mathrm{u}}_{3}$ & $\overrightarrow{\mathrm{u}}_{3}$ & $P_{g}=0$ & $\overrightarrow{\mathrm{u}}=0$ \\
\hline Initial volume fraction & $\begin{array}{c}\alpha_{\text {water }}=1 \\
\alpha_{\text {oil }}=0\end{array}$ & $\begin{array}{c}\alpha_{\text {water }}=1 \\
\alpha_{\text {oil }}=0\end{array}$ & $\begin{array}{l}\alpha_{\text {water }}=0 \\
\alpha_{\text {oil }}=1\end{array}$ & & \\
\hline Initial mass fraction & $\begin{array}{l}C^{\mathrm{a}}{ }_{\mathrm{w}}=1 \\
\mathrm{C}^{\mathrm{b}}{ }_{\mathrm{w}}=0\end{array}$ & $\begin{array}{l}C^{\mathrm{a}}{ }_{\mathrm{w}}=0 \\
\mathrm{C}^{\mathrm{b}}{ }_{\mathrm{w}}=1\end{array}$ & $\begin{array}{l}C^{\mathrm{a}}{ }_{\mathrm{w}}=0 \\
\mathrm{C}^{\mathrm{b}}{ }_{\mathrm{w}}=0\end{array}$ & & \\
\hline
\end{tabular}



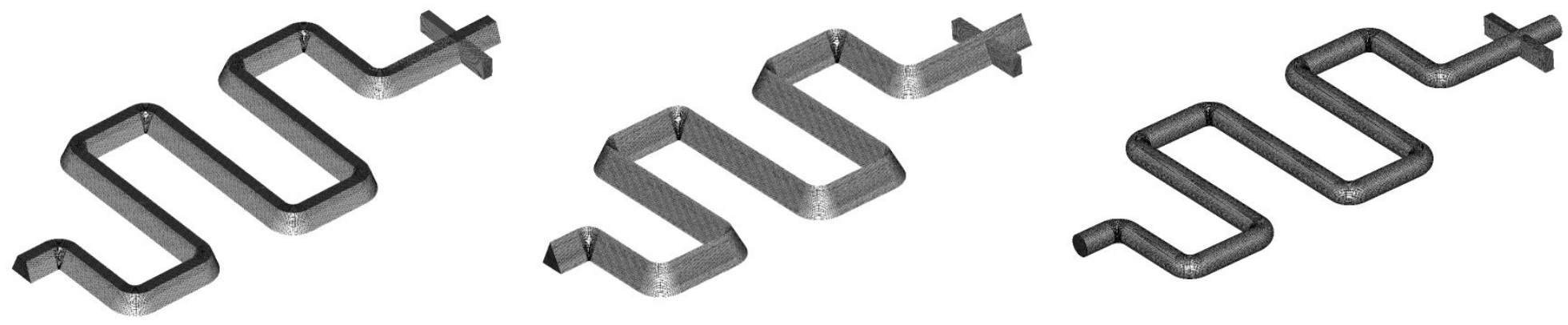

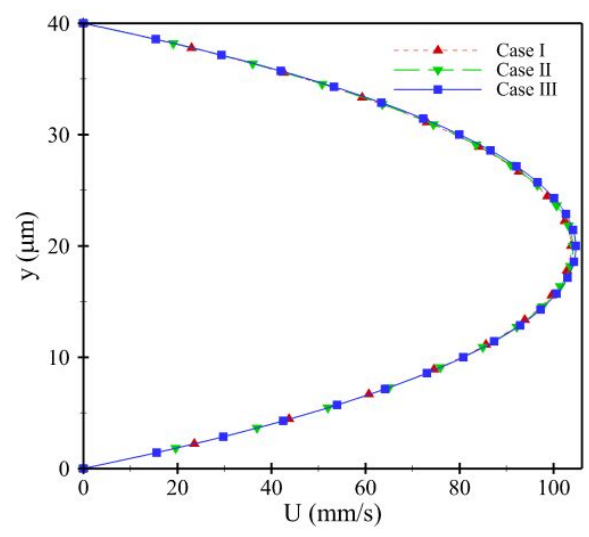

(a)
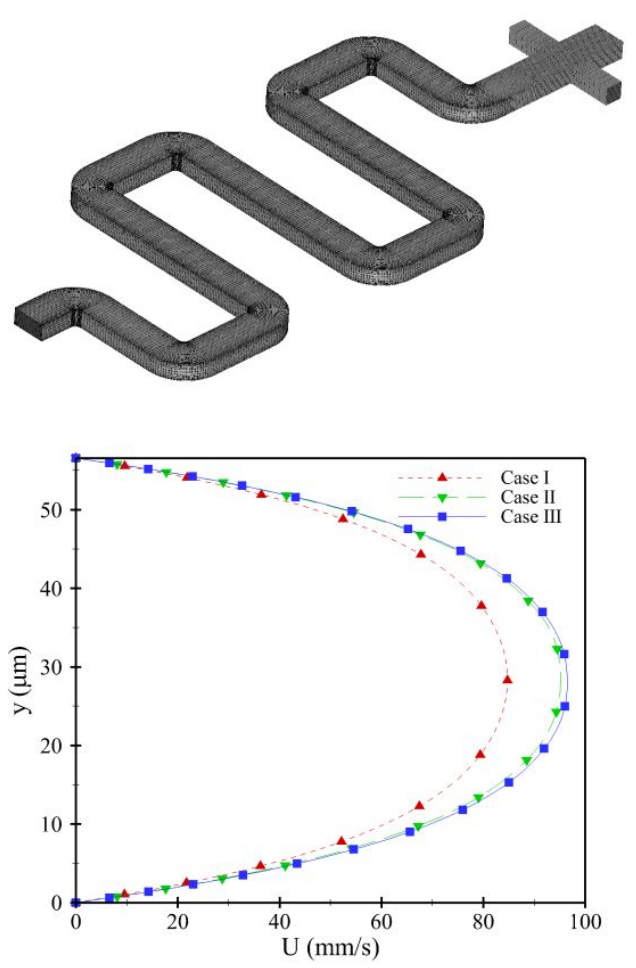

(d)

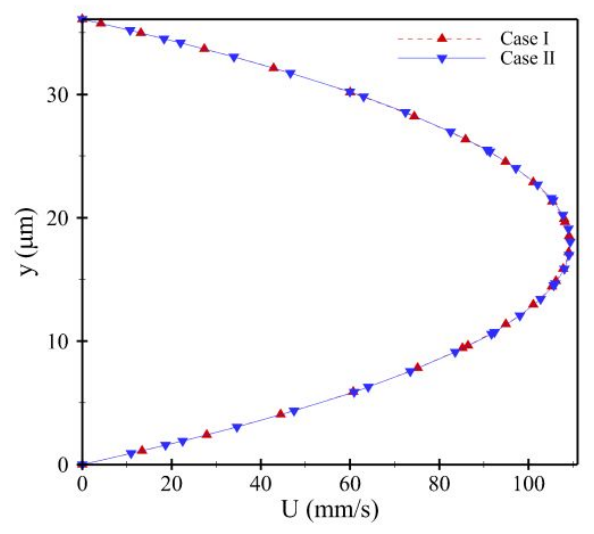

(b)
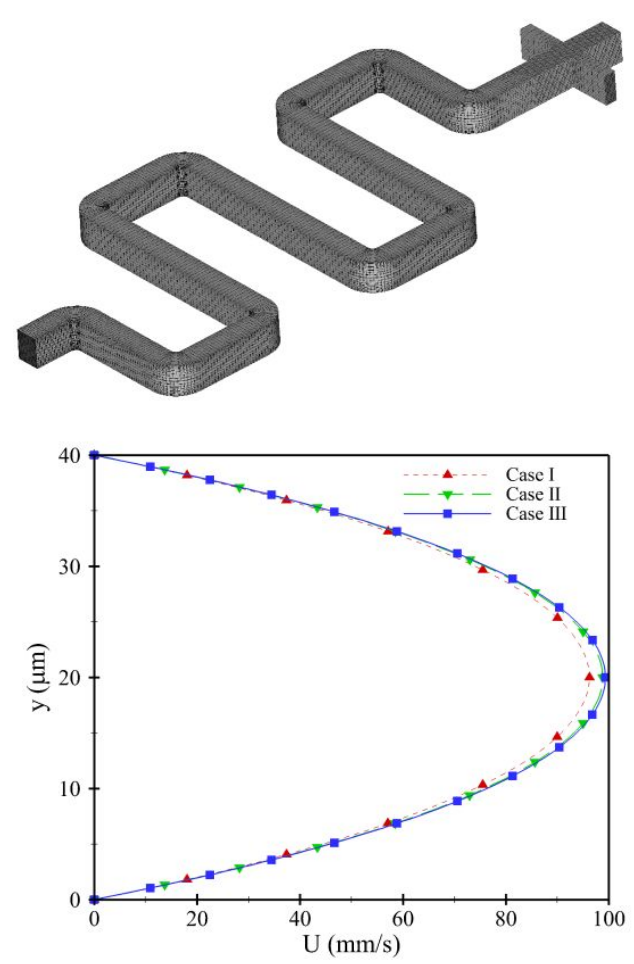

(e)

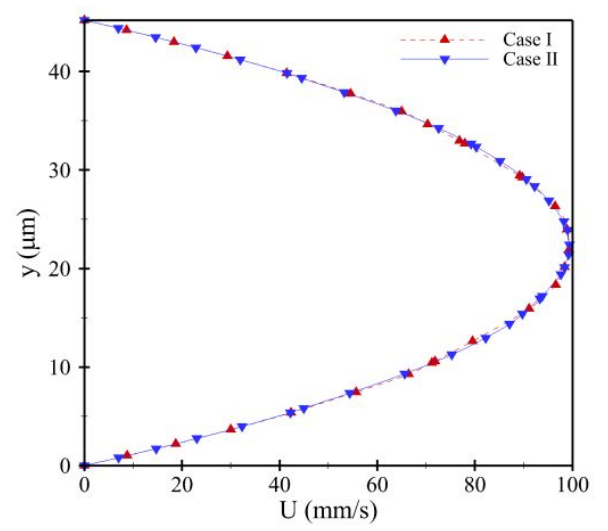

(c)
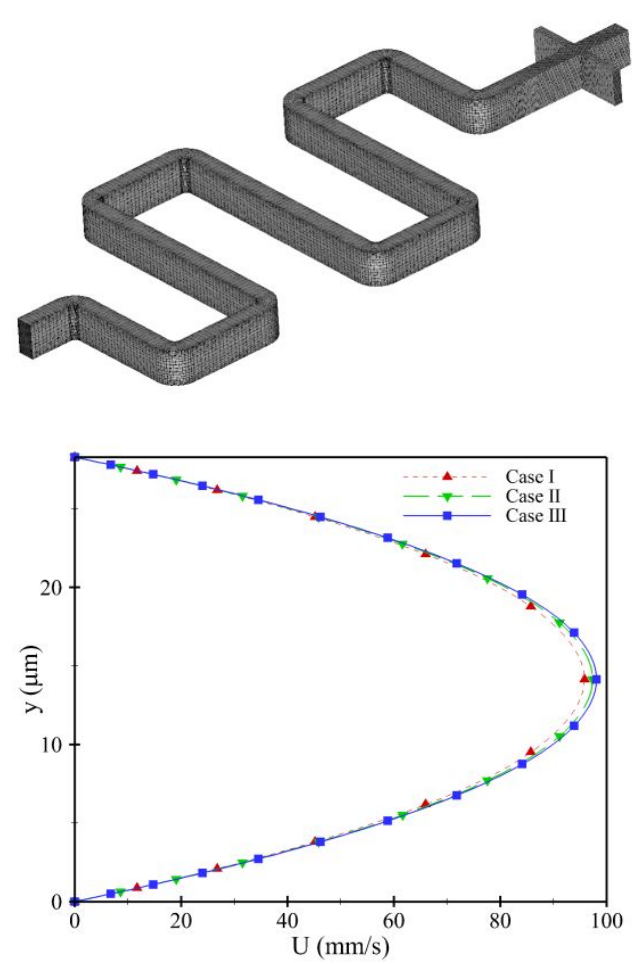

(f)

Figure S1. The mesh configuration of microchannel as well as mesh independence study for (a) trapezoidal; (b) triangular; (c) circular; (d) rectangular with $A R=0.5$; (e) rectangular with $\mathrm{AR}=1.25$; and (f) rectangular with $\mathrm{AR}=2$ cross-sections. 


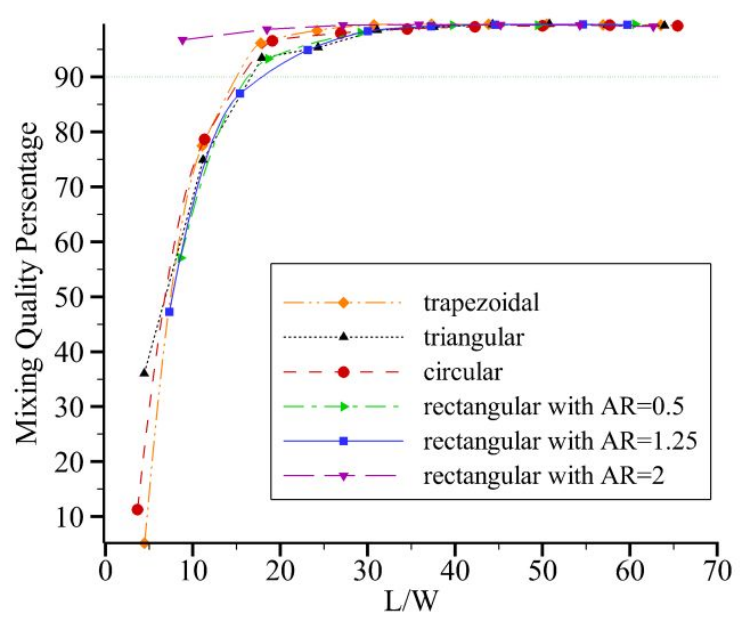

(a)

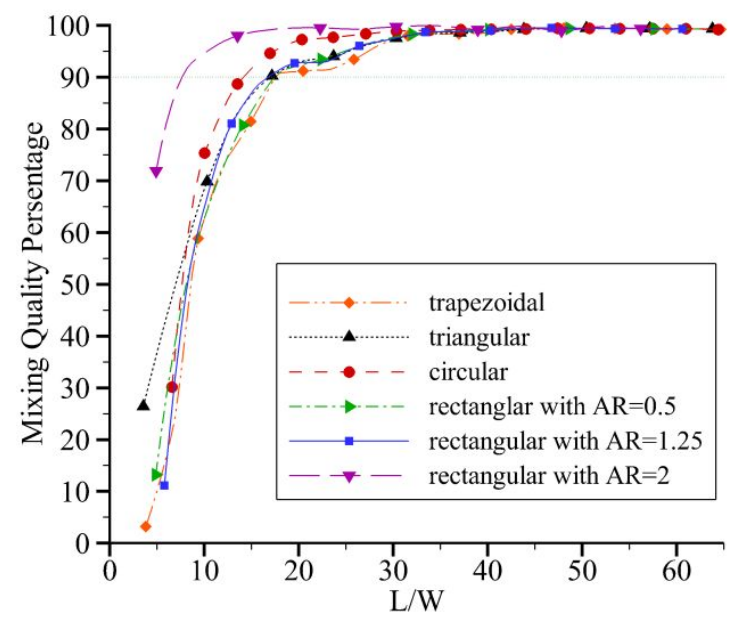

(b)

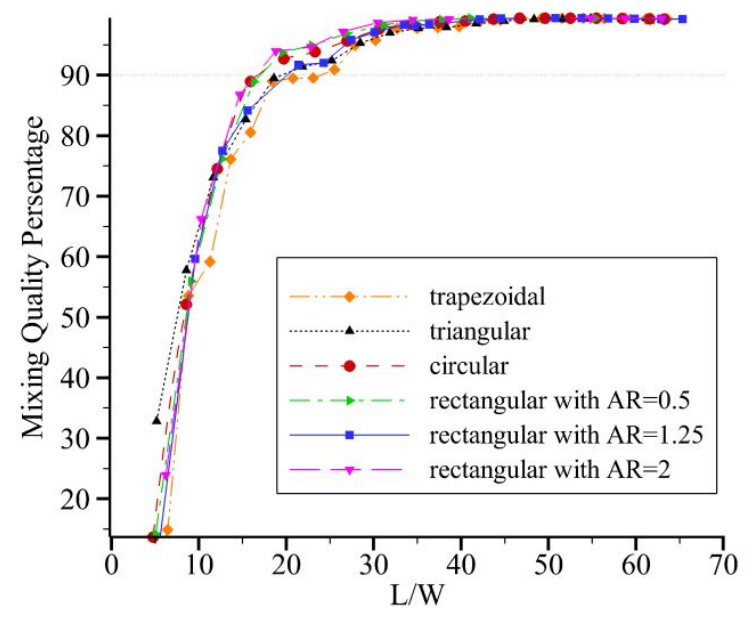

(c)

Figure S2. Comparison of MQ (\%) between all the geometries in the case of (a) WF=0.1; (b) $\mathrm{WF}=0.3$; (c) $\mathrm{WF}=0.5$ by varying the dimensionless length of the generated droplets. 


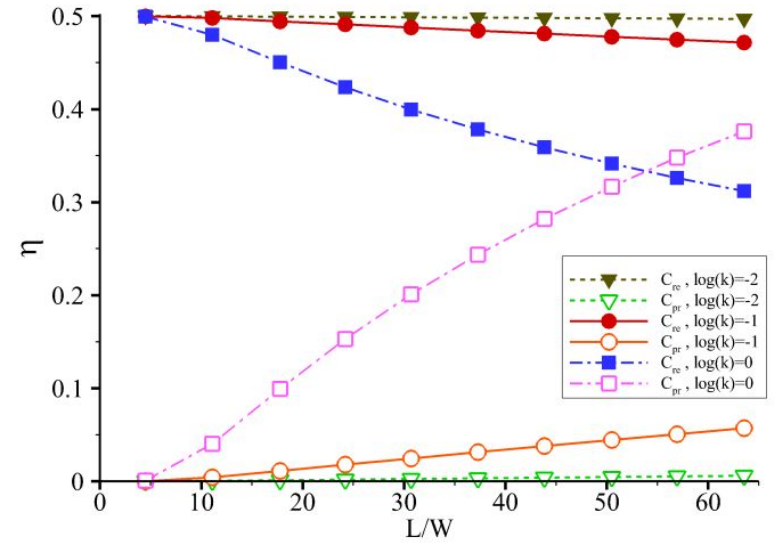

(a)

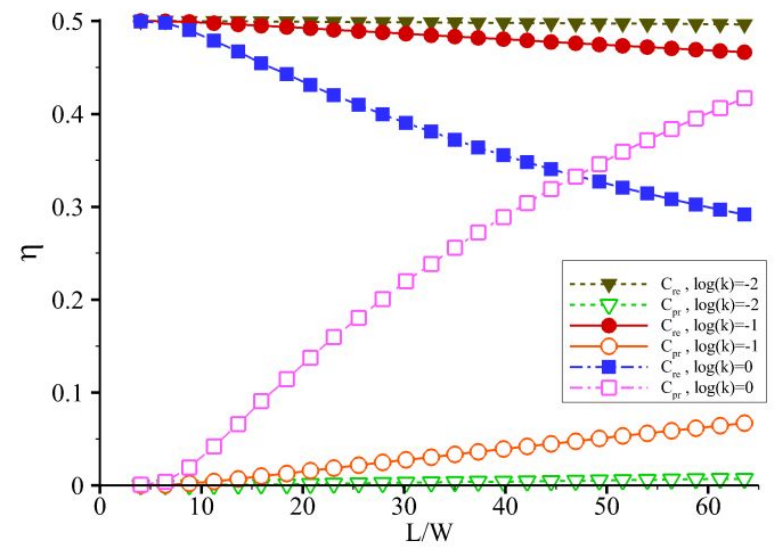

(c)

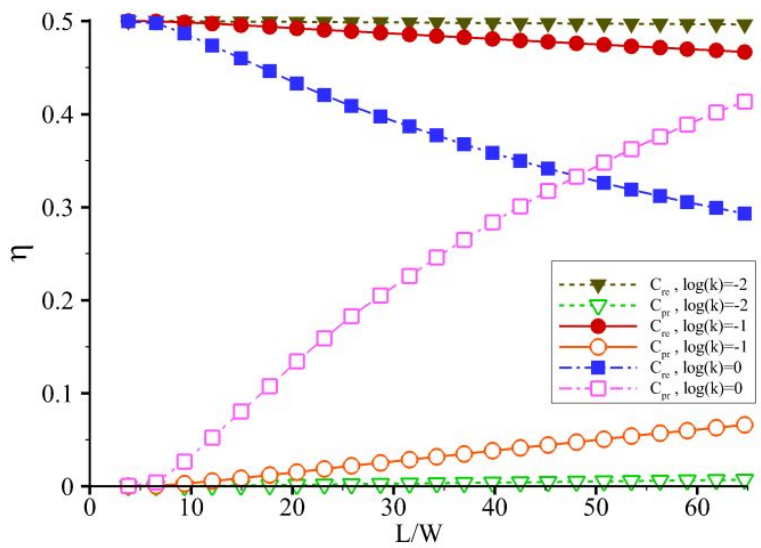

(b)

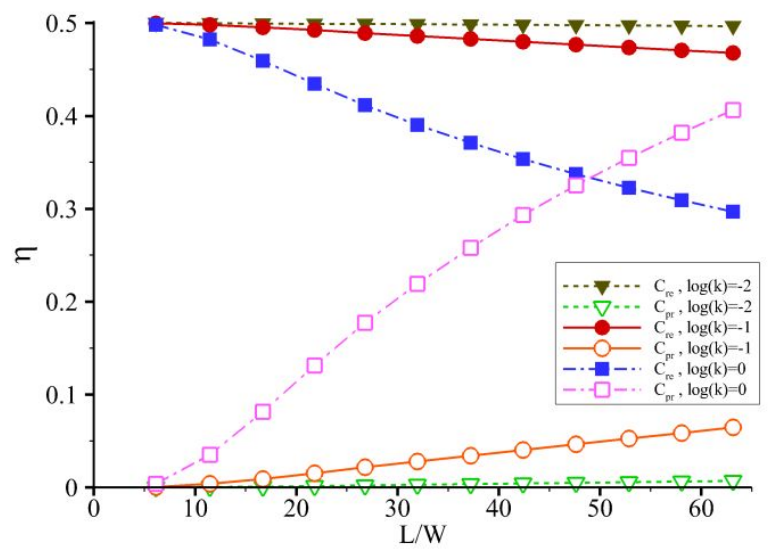

(d)

Figure S3. Illustration of the reactants consumption and product generation of the microchannel with trapezoidal cross-section for: (a) $\mathrm{WF}=0.1$; (b) $\mathrm{WF}=0.3$; (c) $\mathrm{WF}=0.5$; and (d) $\mathrm{WF}=0.7$. 


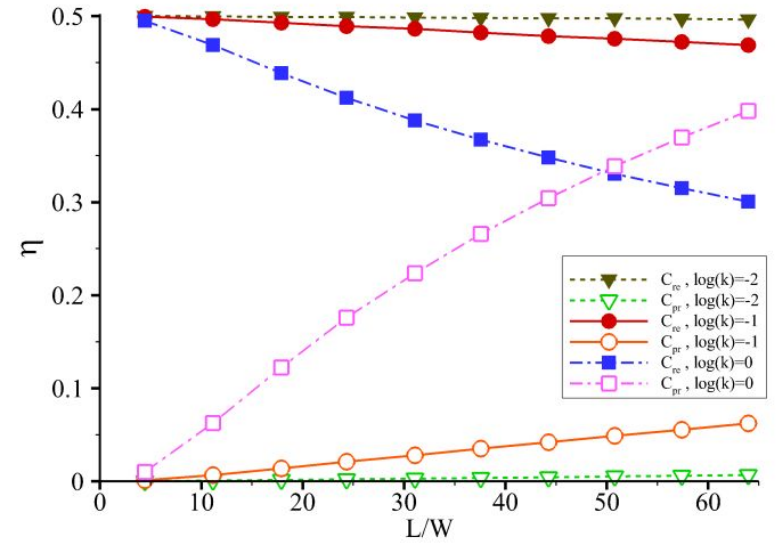

(a)

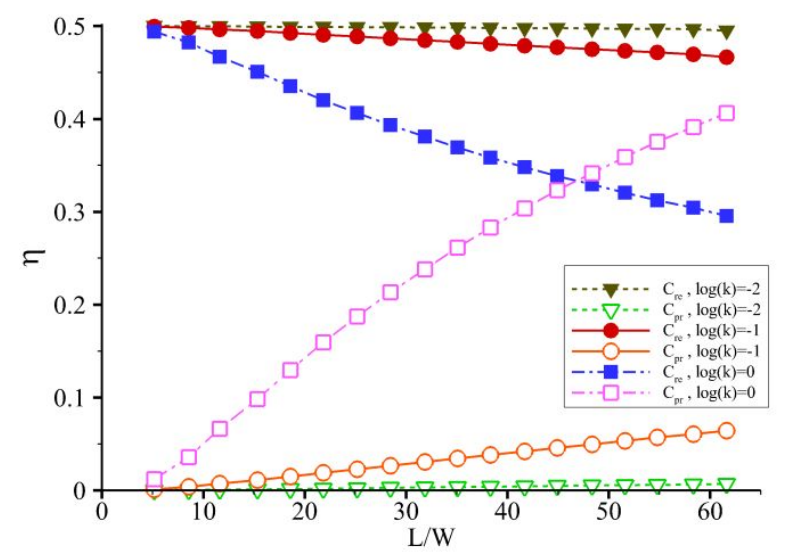

(c)

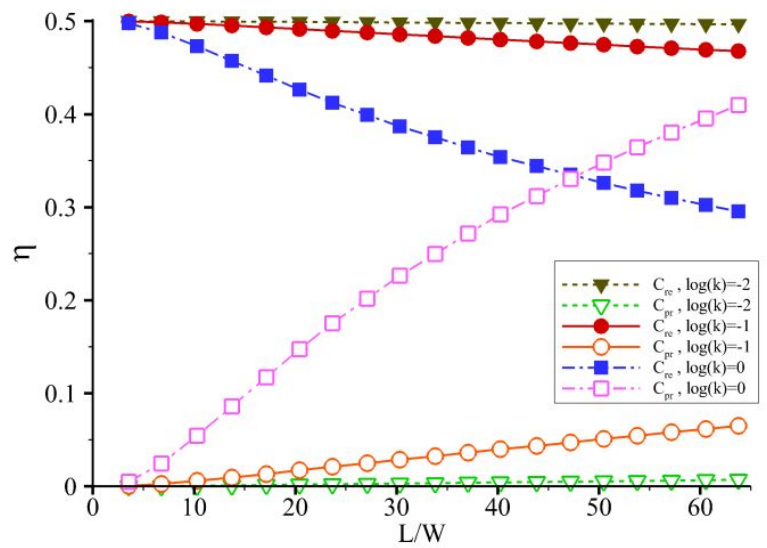

(b)

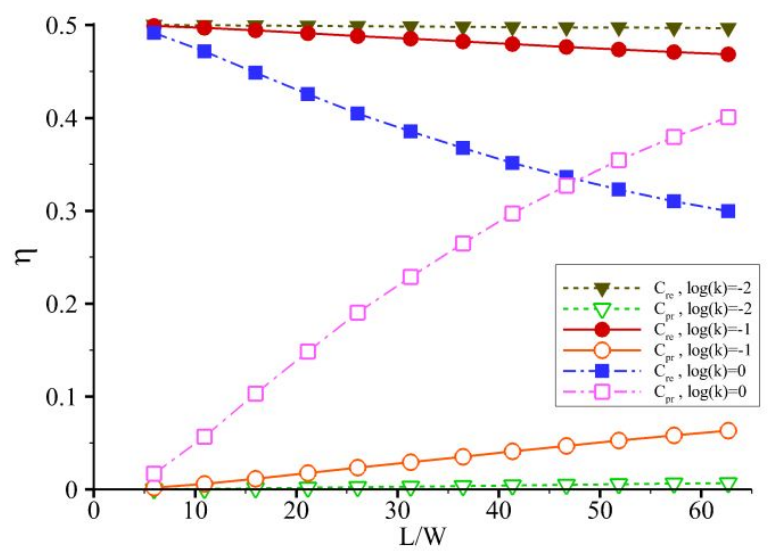

(d)

Figure S4. Illustration of the reactants consumption and product generation of the microchannel with triangular cross-section for: (a) $\mathrm{WF}=0.1$; (b) $\mathrm{WF}=0.3$; (c) $\mathrm{WF}=0.5$; and (d) $\mathrm{WF}=0.7$. 


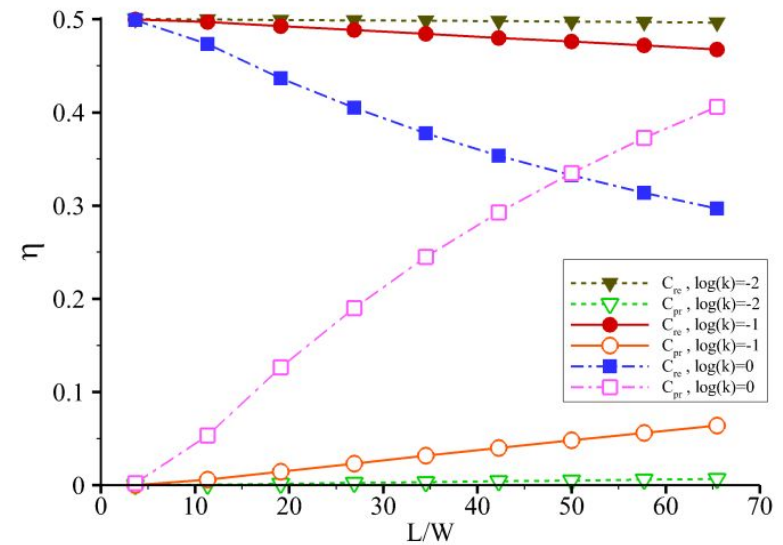

(a)

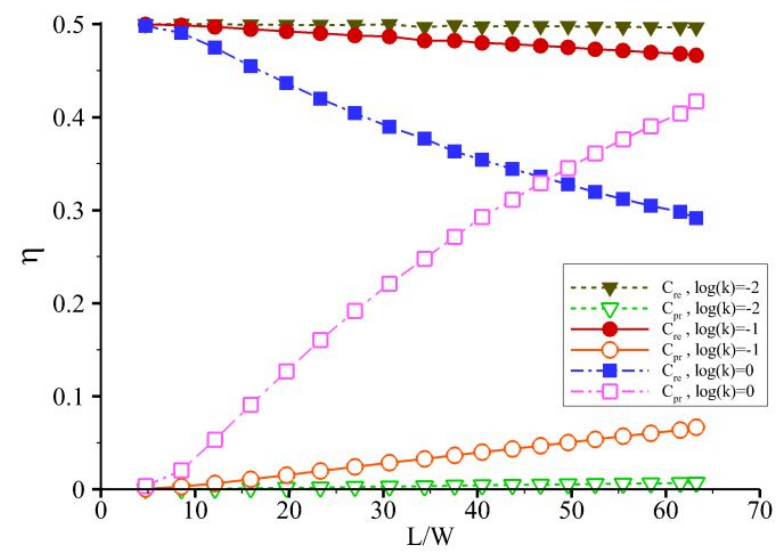

(c)

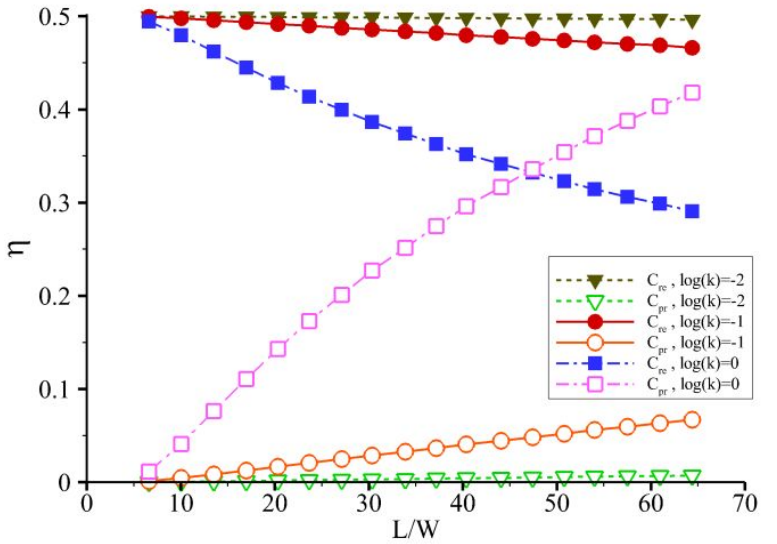

(b)

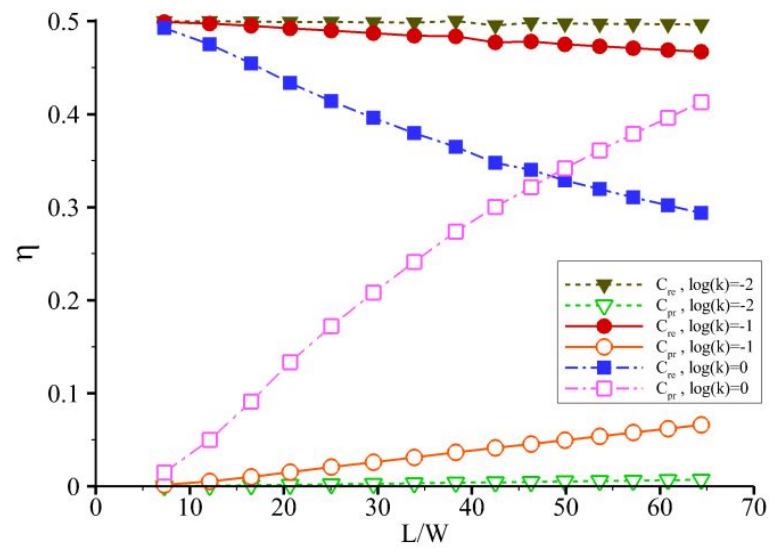

(d)

Figure S5. Illustration of the reactants consumption and product generation of the microchannel with circular cross-section for: (a) $\mathrm{WF}=0.1$; (b) $\mathrm{WF}=0.3$; (c) $\mathrm{WF}=0.5$; and (d) $\mathrm{WF}=0.7$. 


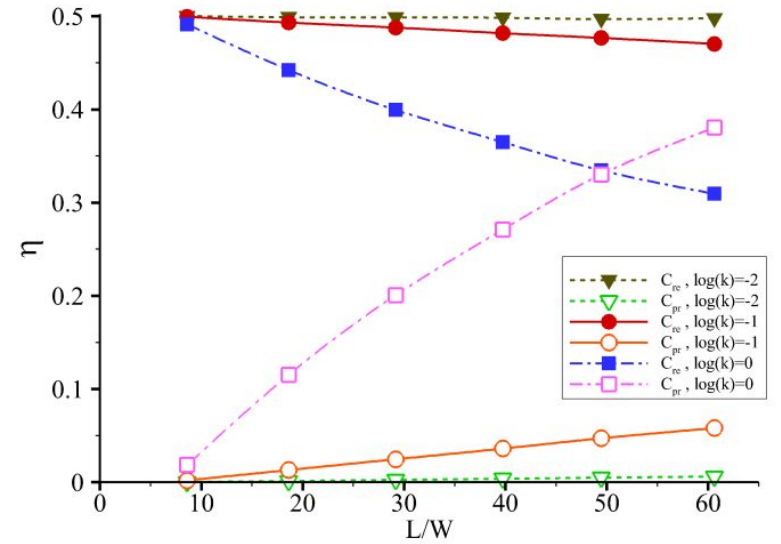

(a)

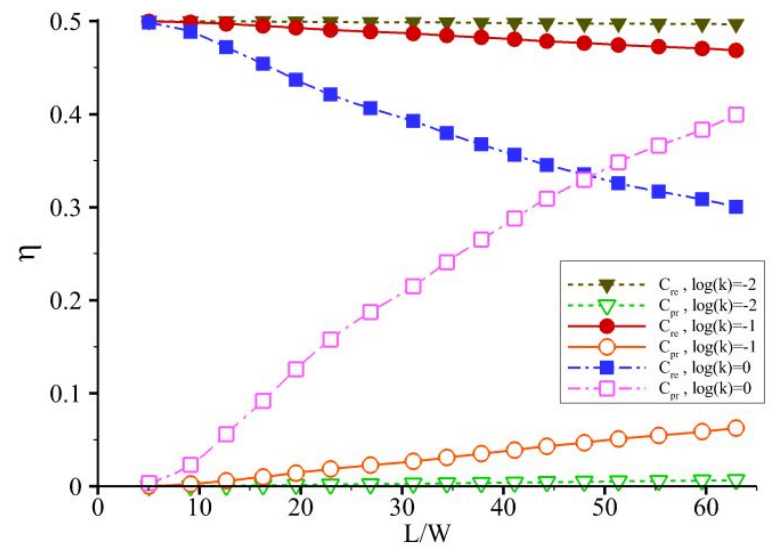

(c)

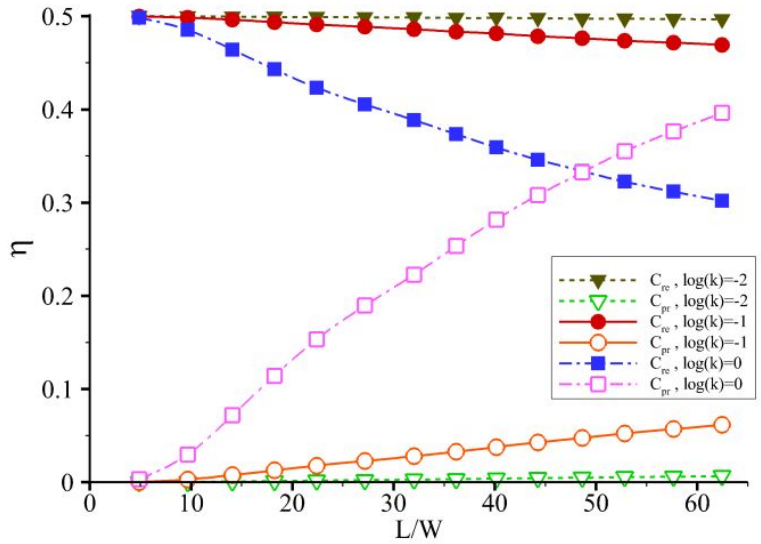

(b)

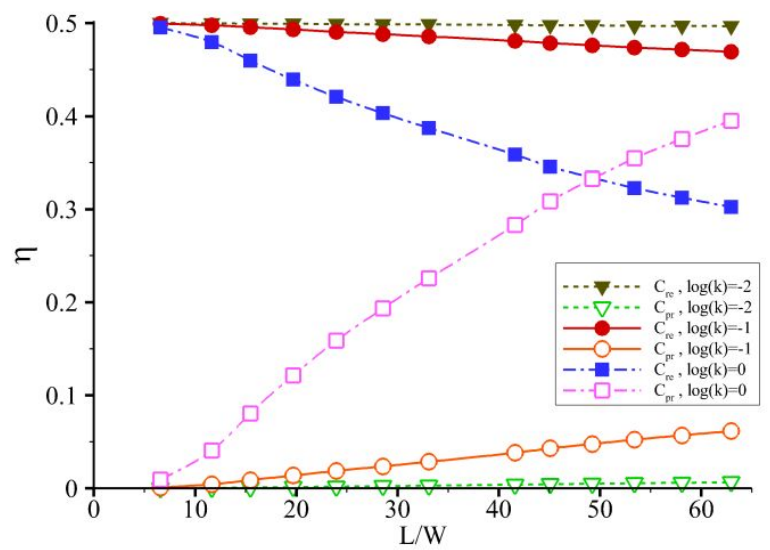

(d)

Figure S6. Illustration of the reactants consumption and product generation of the microchannel with rectangular $(\mathrm{AR}=0.5)$ cross-section for: (a) $\mathrm{WF}=0.1$; (b) $\mathrm{WF}=0.3$; (c) $\mathrm{WF}=0.5$; and (d) $\mathrm{WF}=0.7$. 


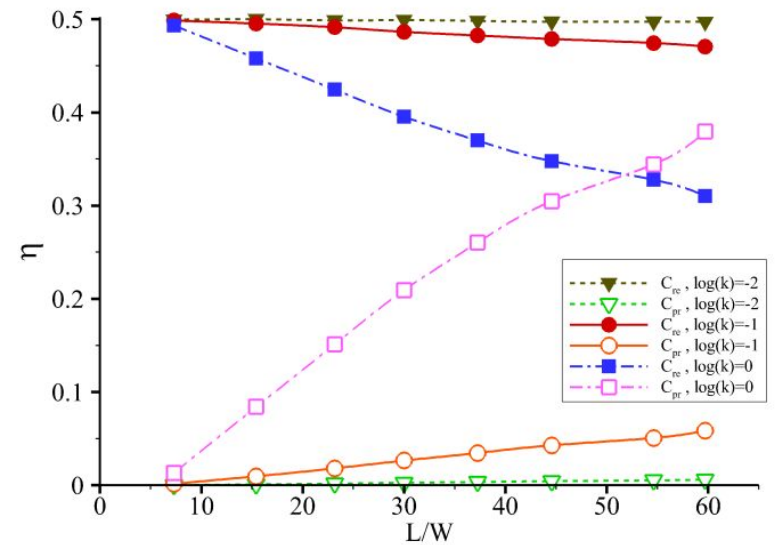

(a)

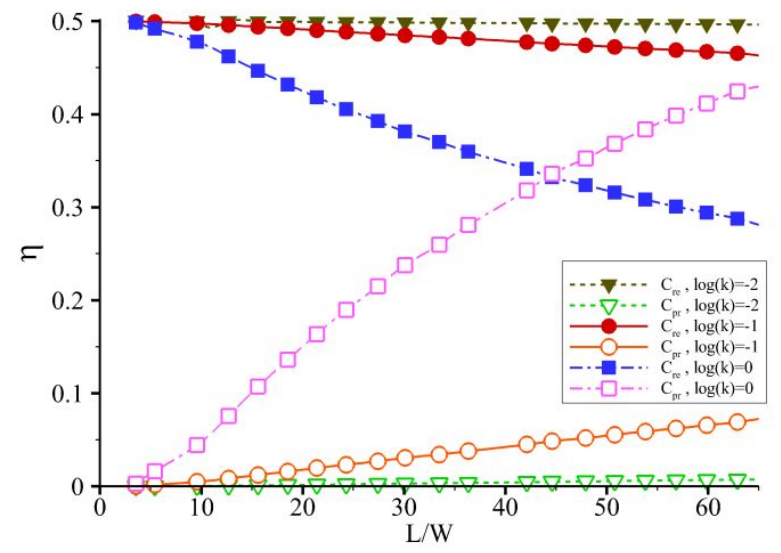

(c)

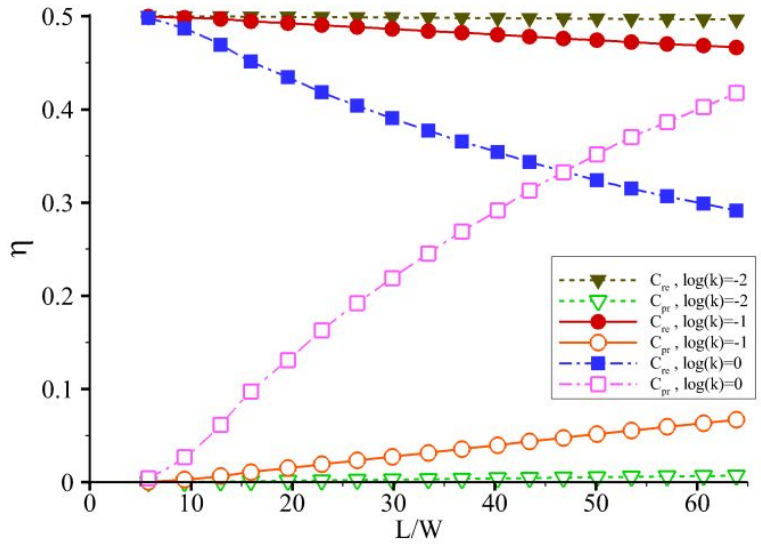

(b)

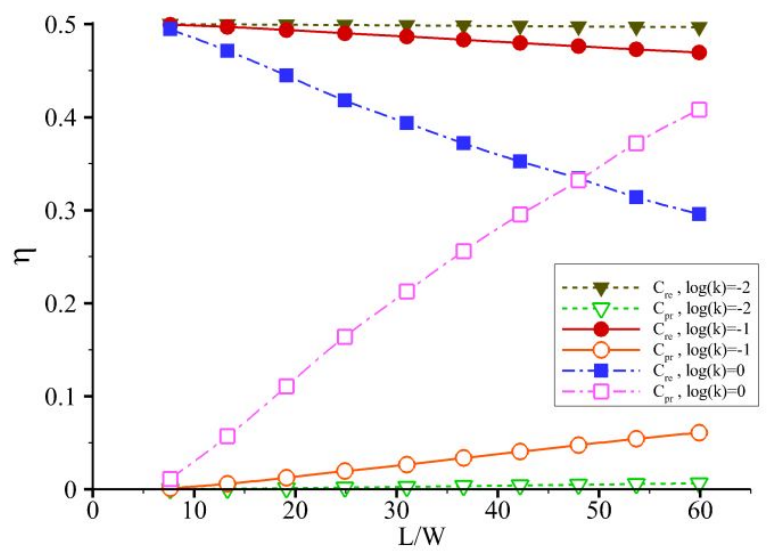

(d)

Figure S7. Illustration of the reactants consumption and product generation of the microchannel with rectangular $(\mathrm{AR}=1.25)$ cross-section for: (a) $\mathrm{WF}=0.1$; (b) $\mathrm{WF}=0.3$; (c) $\mathrm{WF}=0.5$; and (d) $\mathrm{WF}=0.7$. 


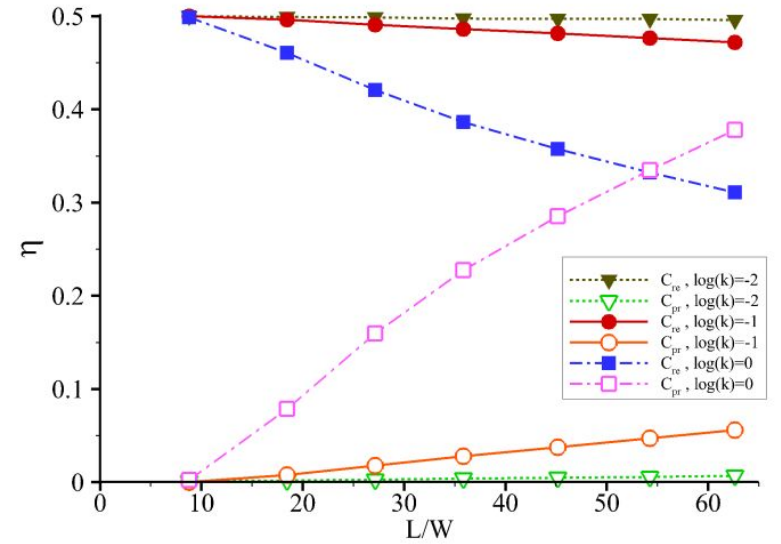

(a)

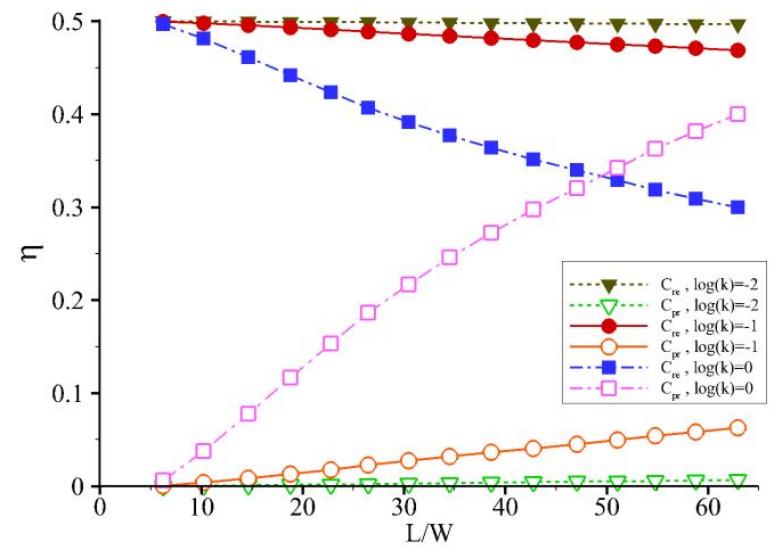

(c)

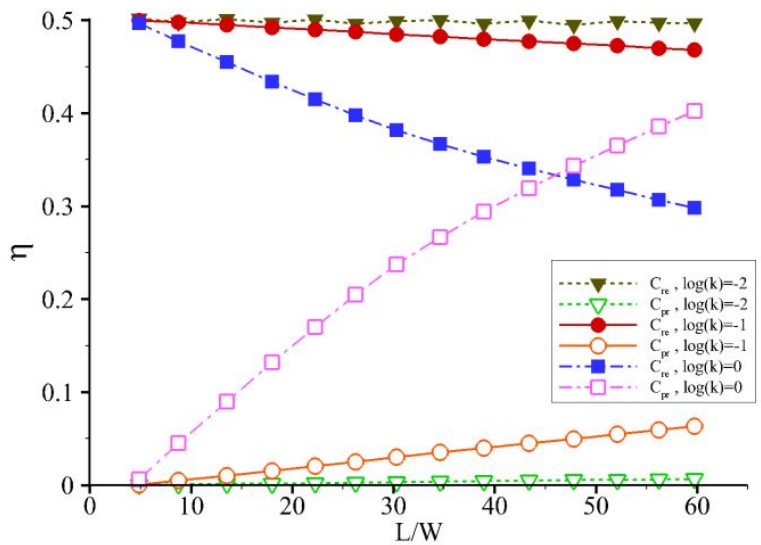

(b)

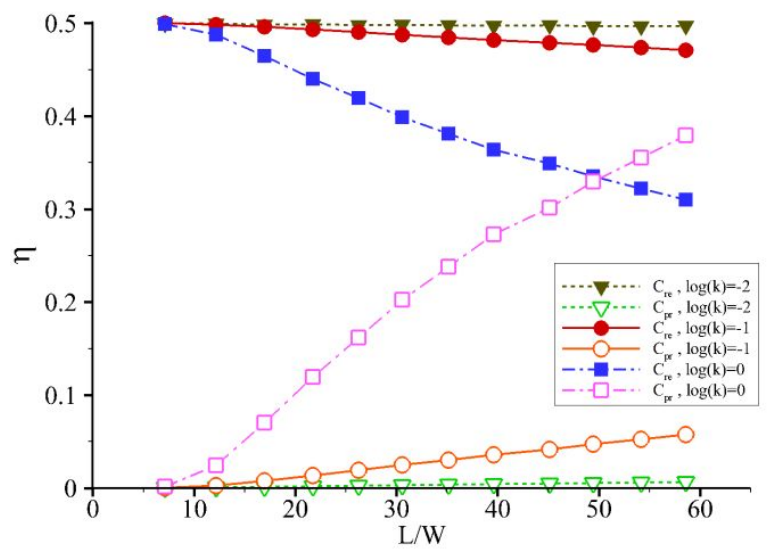

(d)

Figure S8. Illustration of the reactants consumption and product generation of the microchannel with rectangular $(\mathrm{AR}=2)$ cross-section for: (a) $\mathrm{WF}=0.1$; (b) $\mathrm{WF}=0.3$; (c) $\mathrm{WF}=0.5$; and (d) $\mathrm{WF}=0.7$. 


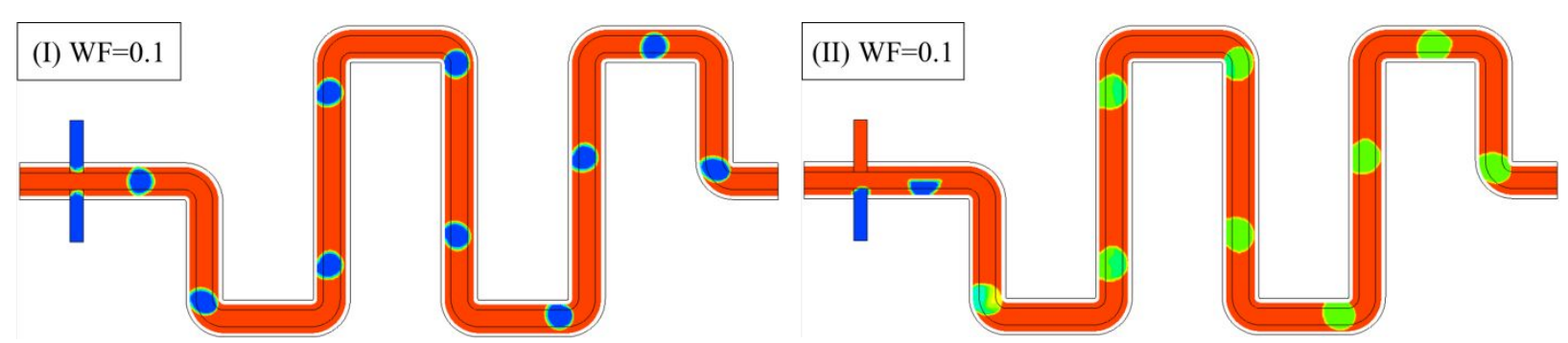

(a)

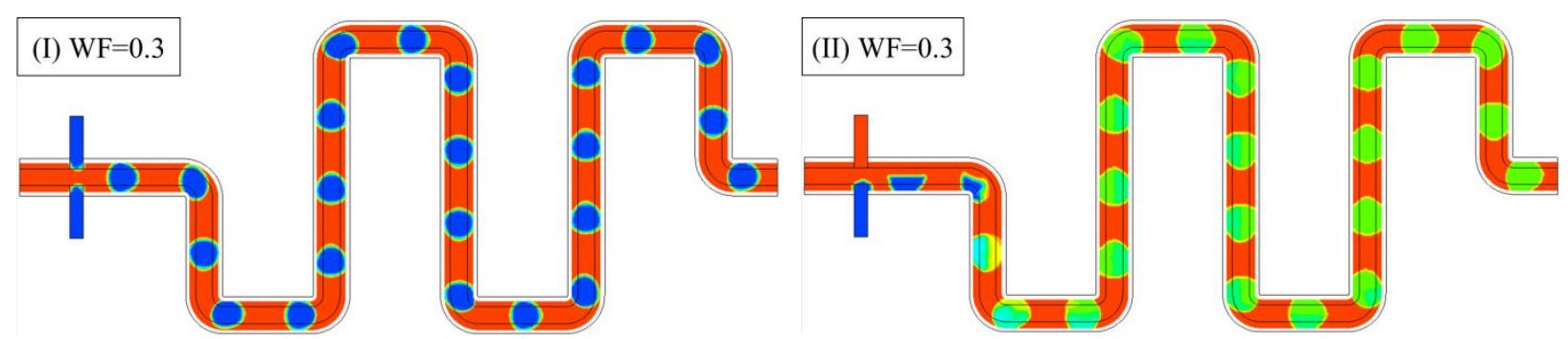

(b)

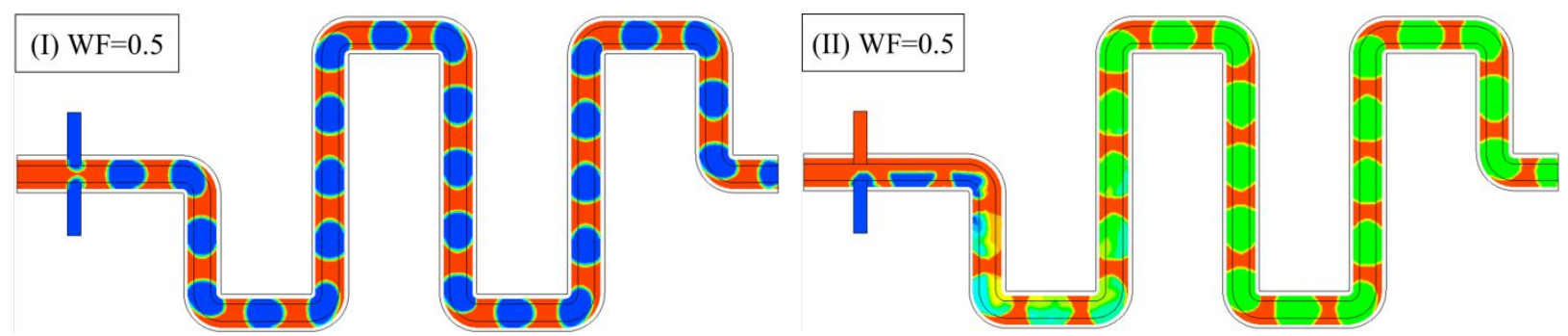

(c)

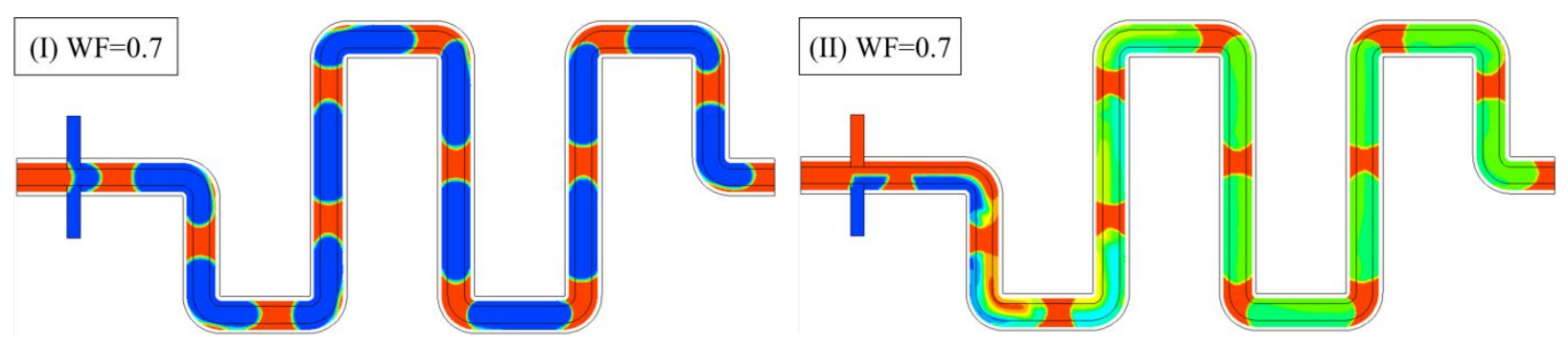

(d)

The volume fraction of the water phase:

$\begin{array}{llllllllllll}0 & 0.1 & 0.2 & 0.3 & 0.4 & 0.5 & 0.6 & 0.7 & 0.8 & 0.9 & 1\end{array}$

Mass fraction of species ' $b$ ':

$\begin{array}{lllllllllllll}0 & 0.1 & 0.2 & 0.3 & 0.4 & 0.5 & 0.6 & 0.7 & 0.8 & 0.9 & 1\end{array}$

Figure S9. Droplet formation (I) and mass fraction of species ' $b$ ' (II) inside the microchannel with trapezoidal cross-section for WF corresponds to (a) 0.1 ; (b) 0.3 ; (c) 0.5 ; and (d) 0.7 . 


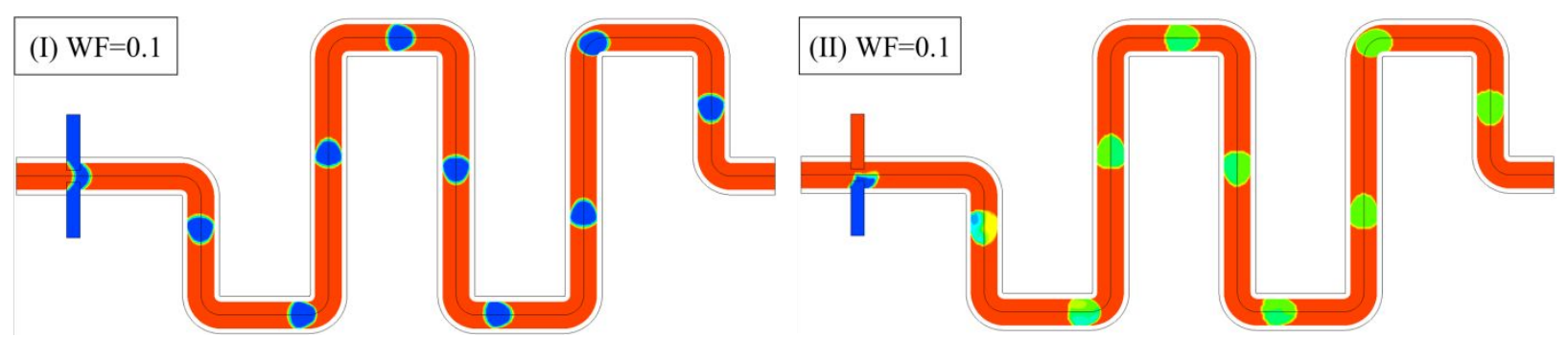

(a)

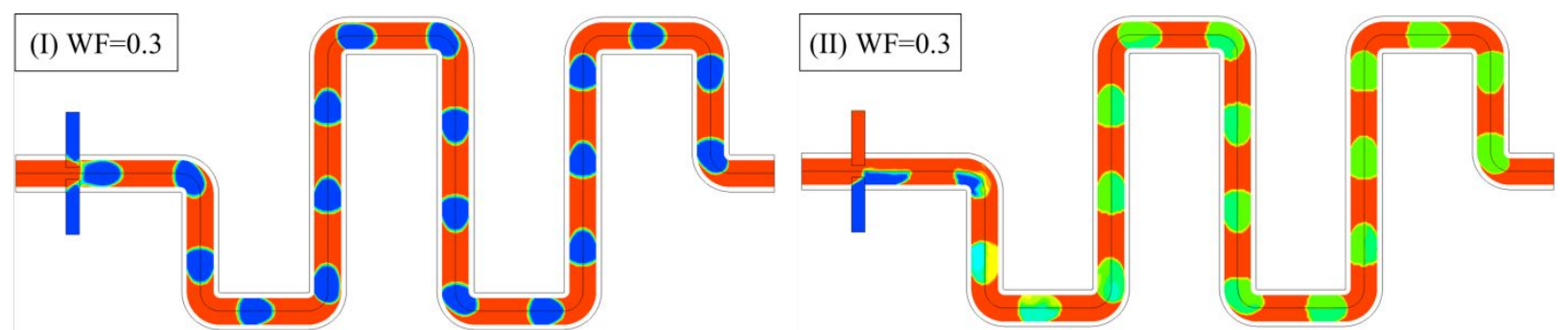

(b)

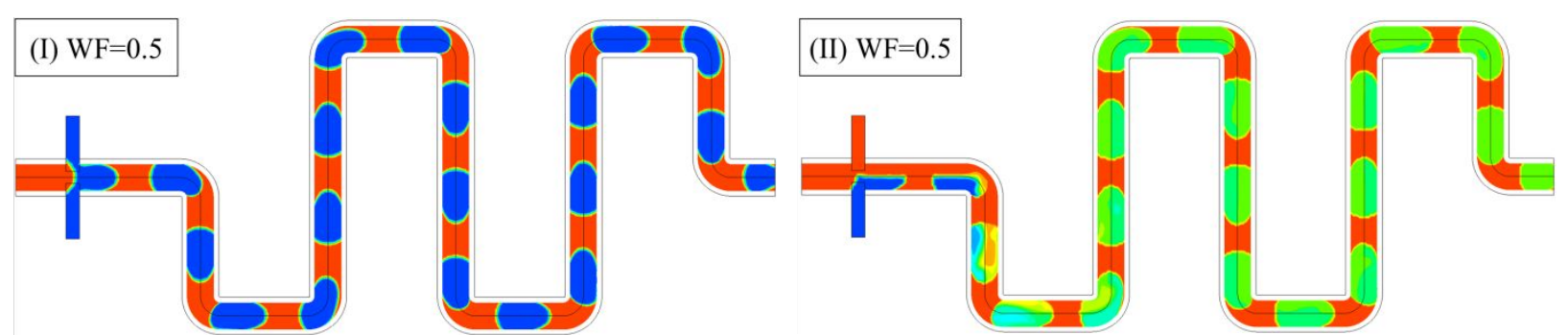

(c)

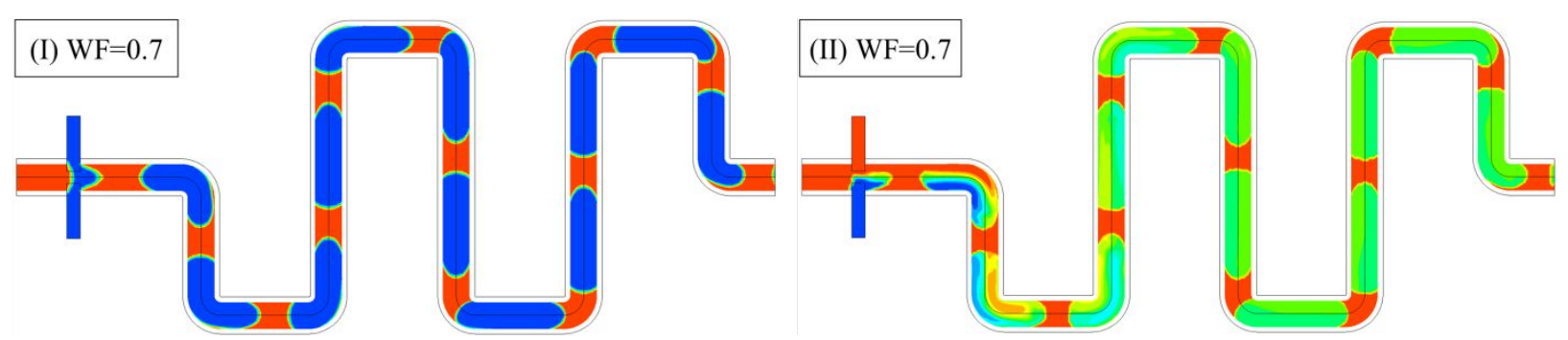

(d)

The volume fraction of the water phase:

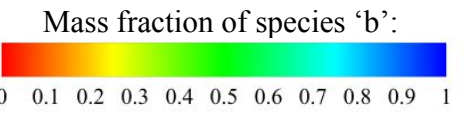

$\begin{array}{llllllllllll}0 & 0.1 & 0.2 & 0.3 & 0.4 & 0.5 & 0.6 & 0.7 & 0.8 & 0.9 & 1\end{array}$

Figure S10. Droplet formation (I) and mass fraction of species ' $b$ ' (II) inside the microchannel with triangular cross-section for WF corresponds to (a) 0.1 ; (b) 0.3 ; (c) 0.5 ; and (d) 0.7 . 


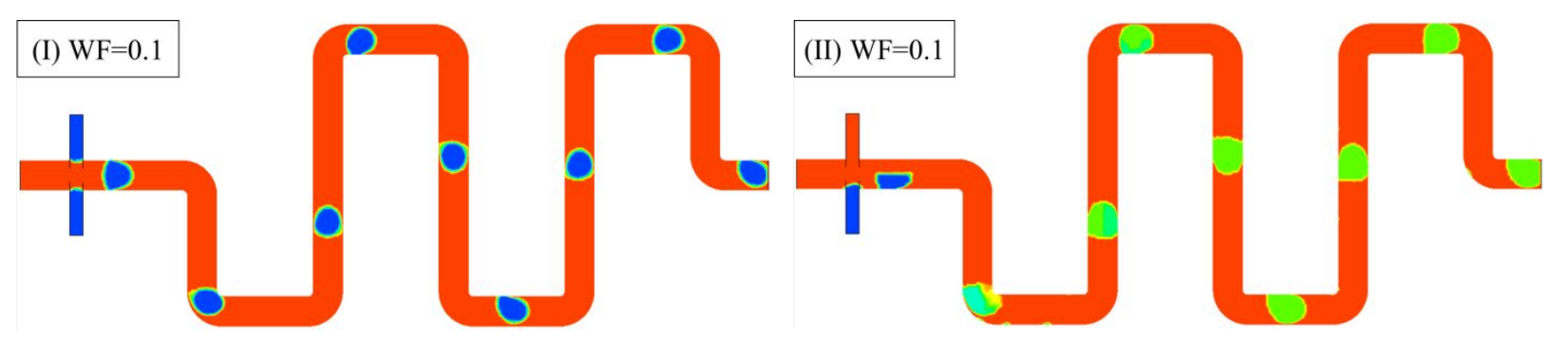

(a)

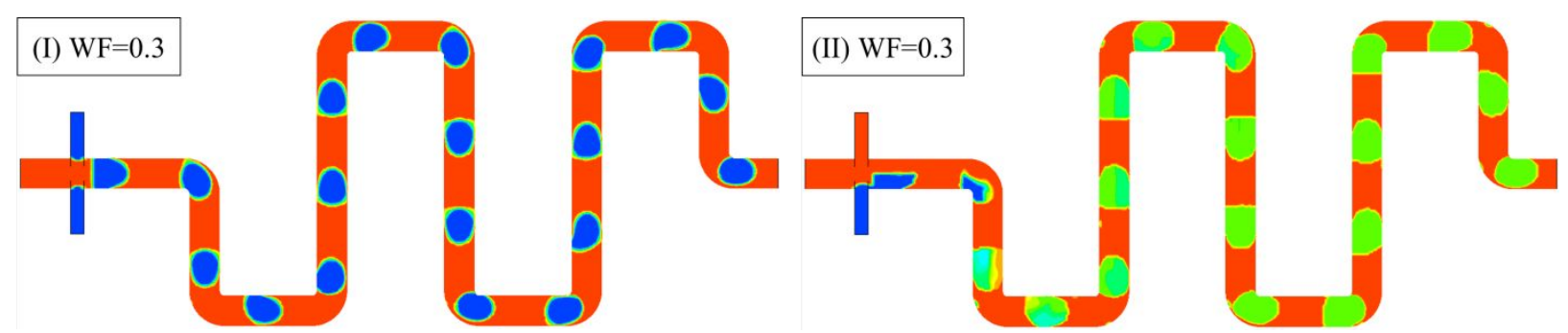

(b)

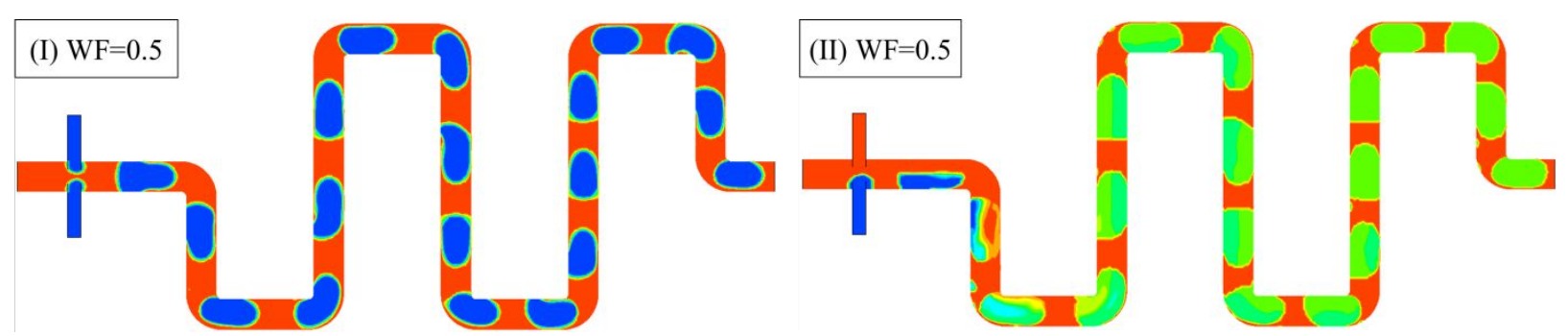

(c)

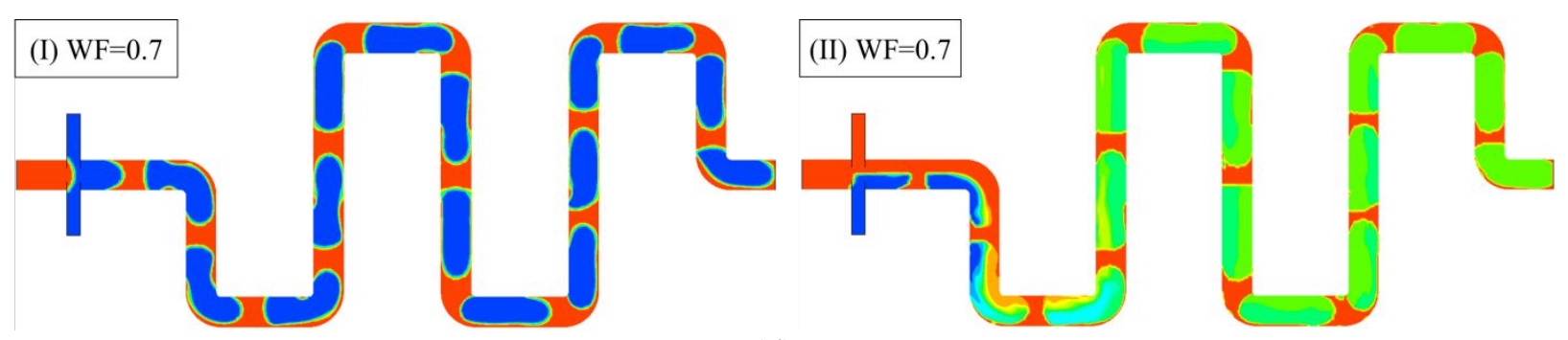

(d)

The volume fraction of the water phase:

$\begin{array}{llllllllllll}0 & 0.1 & 0.2 & 0.3 & 0.4 & 0.5 & 0.6 & 0.7 & 0.8 & 0.9 & 1\end{array}$

Mass fraction of species ' $b$ ':

$\begin{array}{llllllllllll}0 & 0.1 & 0.2 & 0.3 & 0.4 & 0.5 & 0.6 & 0.7 & 0.8 & 0.9 & 1\end{array}$

Figure S11. Droplet formation (I) and mass fraction of species ' $b$ ' (II) inside the microchannel with circular cross-section for WF corresponds to (a) 0.1 ; (b) 0.3 ; (c) 0.5 ; and (d) 0.7 . 


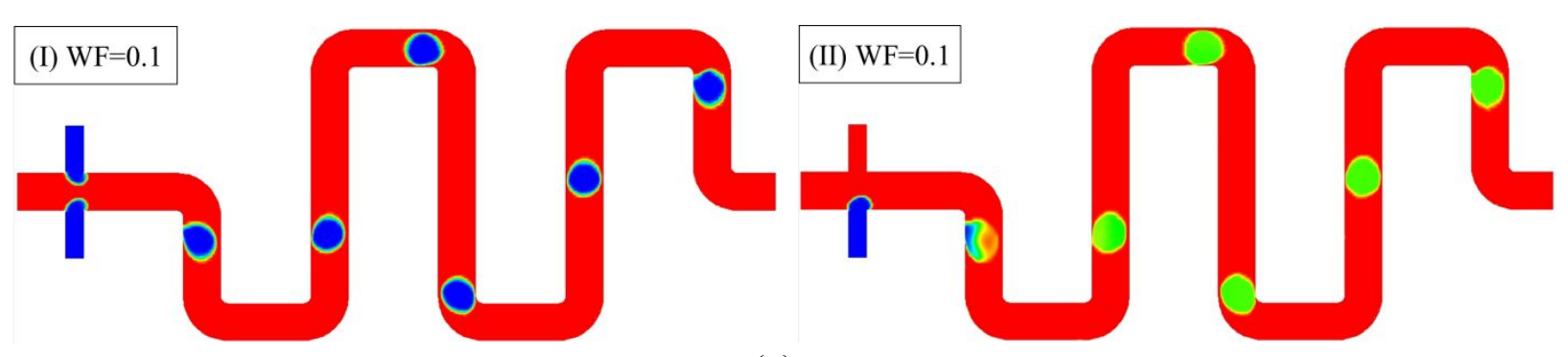

(a)

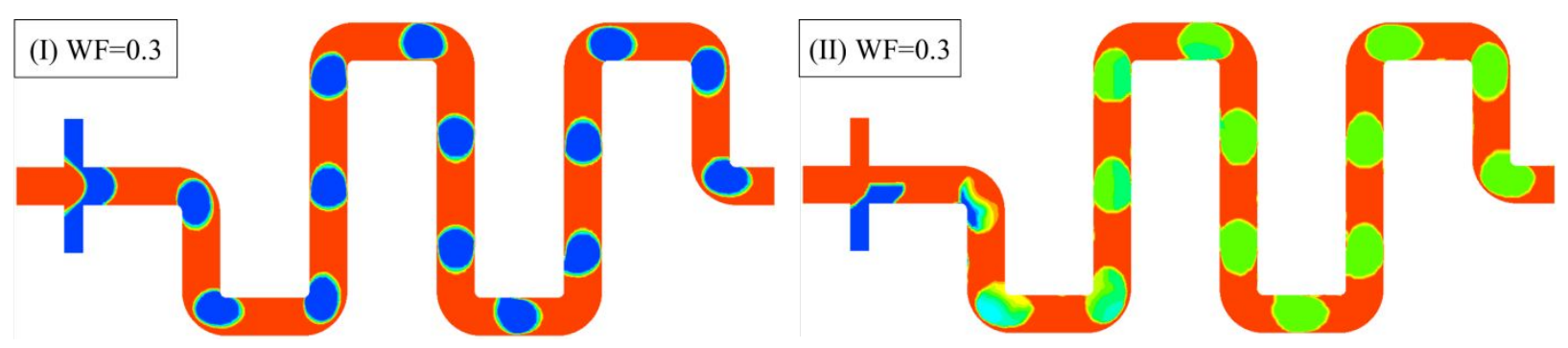

(b)

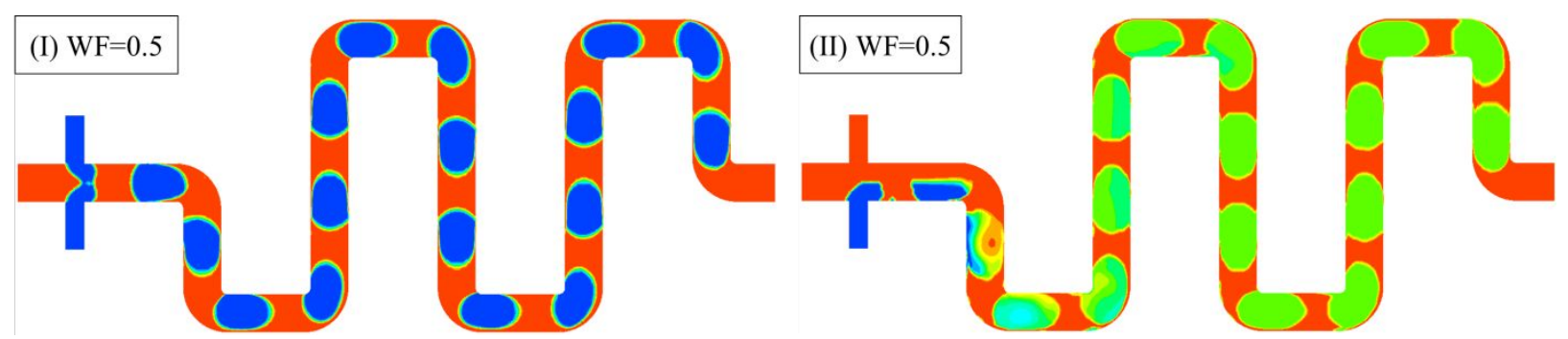

(c)

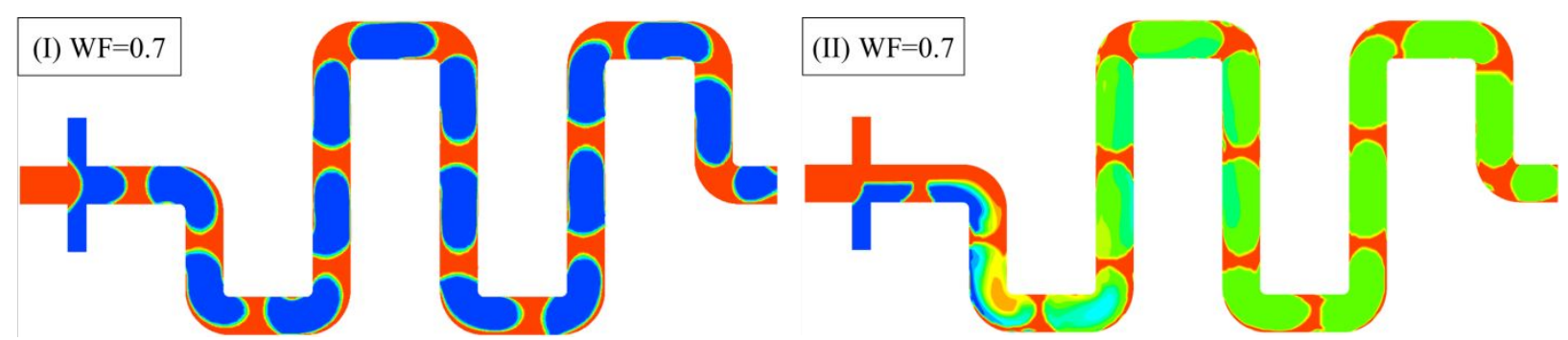

(d)

The volume fraction of the water phase:

$\begin{array}{lllllllllllll}0 & 0.1 & 0.2 & 0.3 & 0.4 & 0.5 & 0.6 & 0.7 & 0.8 & 0.9 & 1\end{array}$

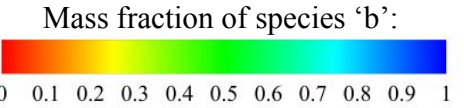

Figure S12. Droplet formation (I) and mass fraction of species ' $b$ ' (II) inside the microchannel with rectangular cross-section with $A R=0.5$ for WF corresponds to (a) 0.1 ; (b) 0.3 ; (c) 0.5 ; and (d) 0.7 . 


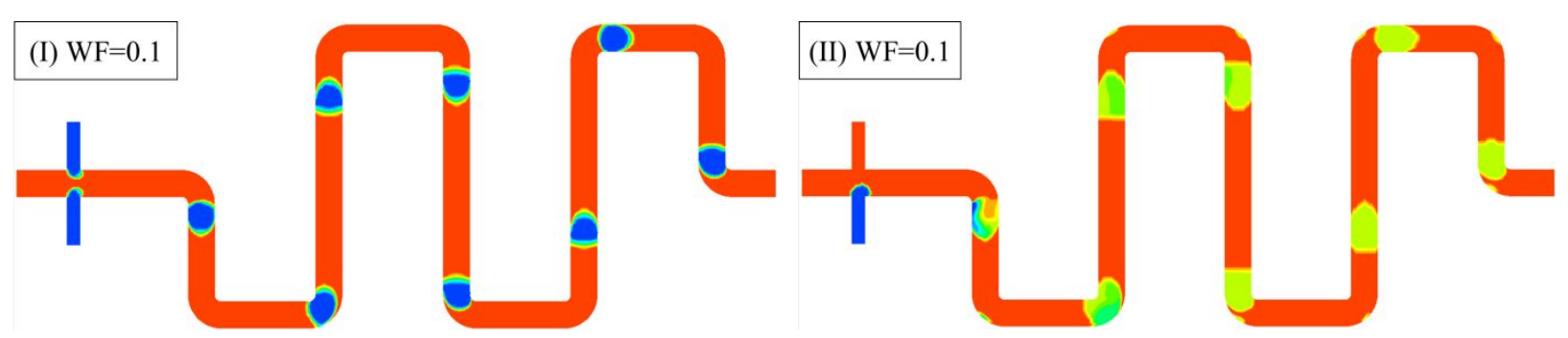

(a)

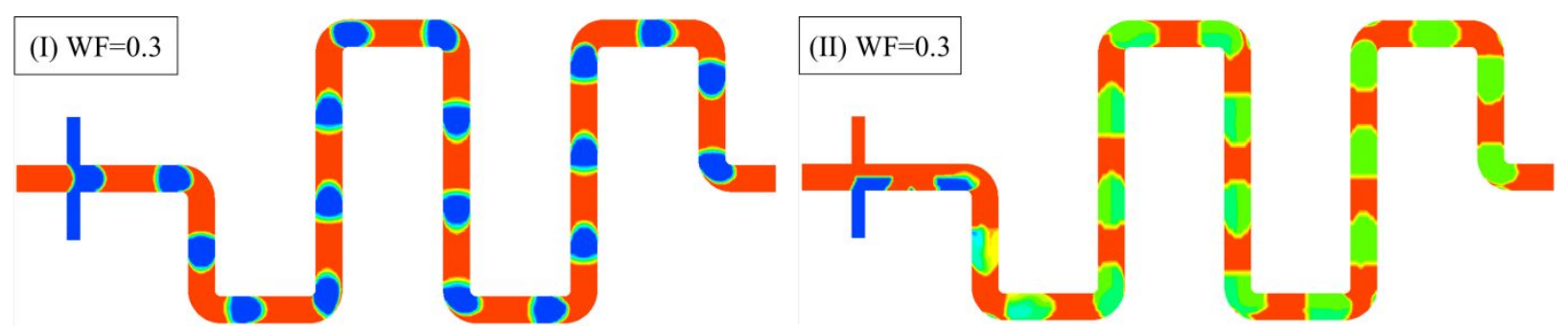

(b)

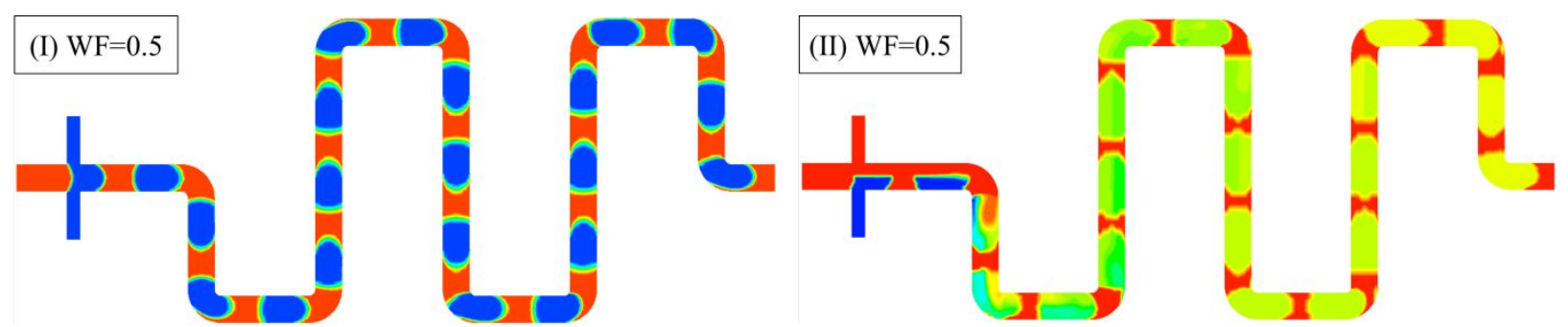

(c)

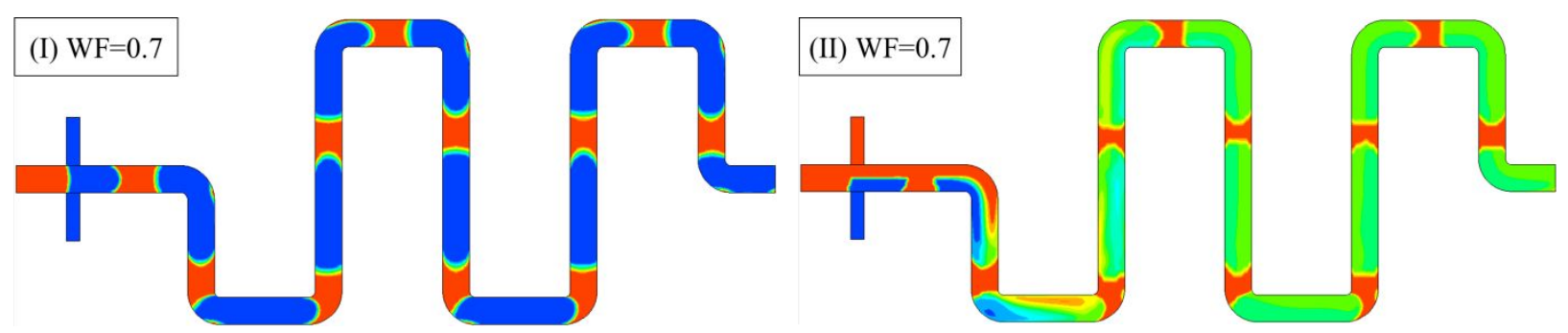

(d)

The volume fraction of the water phase: $\begin{array}{lllllllllll}0 & 0.1 & 0.2 & 0.3 & 0.4 & 0.5 & 0.6 & 0.7 & 0.8 & 0.9 & 1\end{array}$
Mass fraction of species ' $b$ ':

$\begin{array}{lllllllllll}0 & 0.1 & 0.2 & 0.3 & 0.4 & 0.5 & 0.6 & 0.7 & 0.8 & 0.9 & 1\end{array}$

Figure S13. Droplet formation (I) and mass fraction of species ' $b$ ' (II) inside the microchannel with rectangular cross-section with $\mathrm{AR}=1.25$ for $\mathrm{WF}$ corresponds to (a) 0.1 ; (b) 0.3 ; (c) 0.5 ; and (d) 0.7 . 


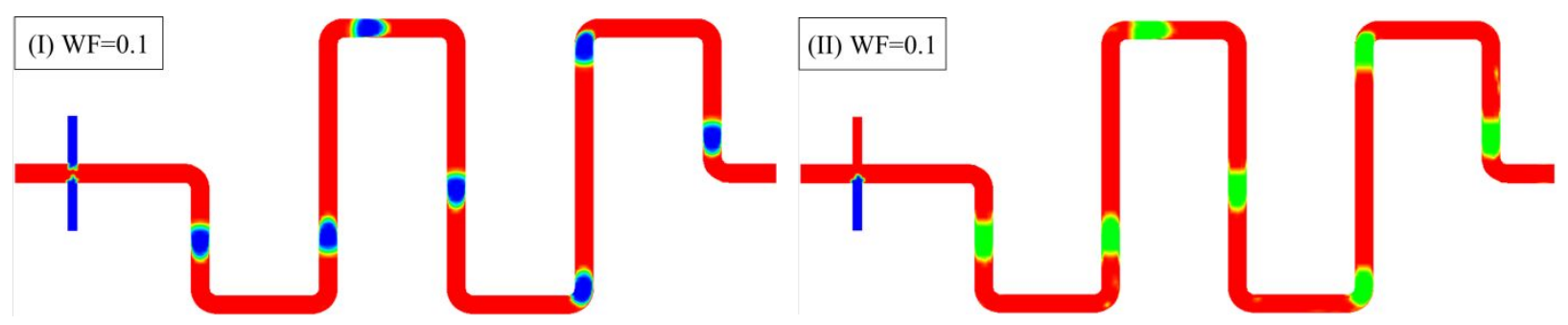

(a)

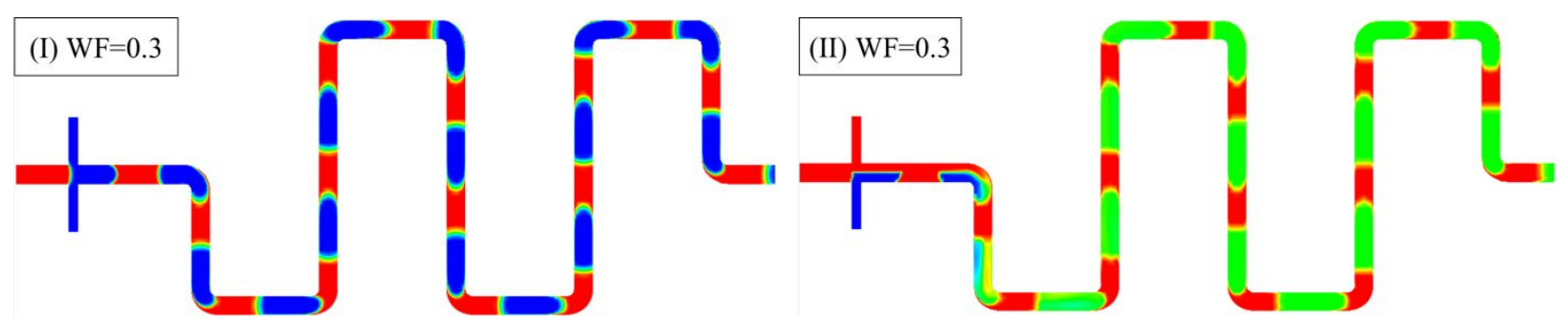

(b)

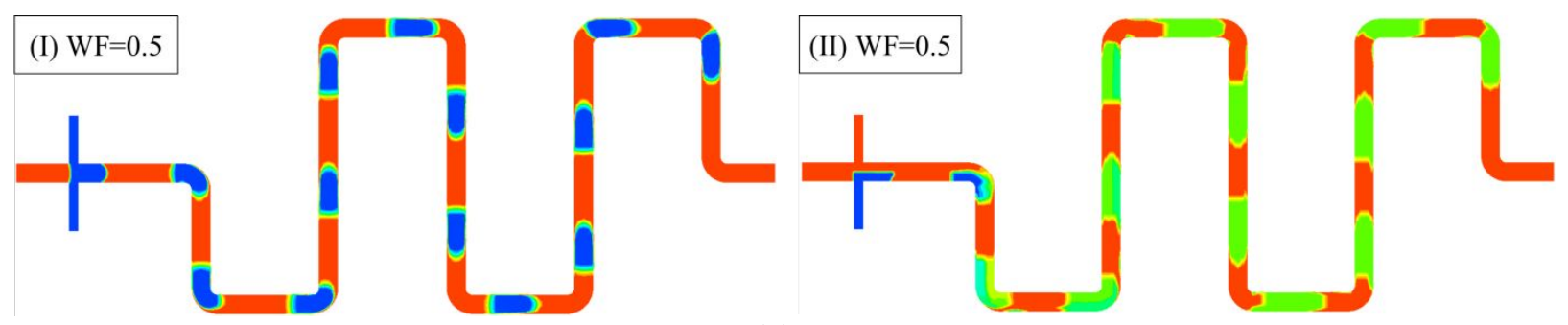

(c)

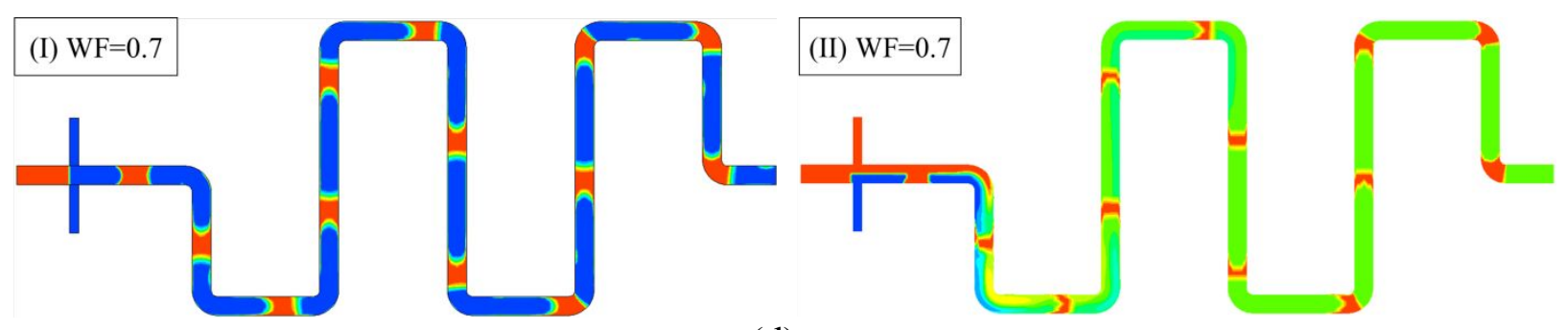

(d)

The volume fraction of the water phase: $\begin{array}{llllllllll}0 & 0.1 & 0.2 & 0.3 & 0.4 & 0.5 & 0.6 & 0.7 & 0.8 & 0.9\end{array}$ Mass fraction of species ' $b$ ': $\begin{array}{lllllllllll}0 & 0.1 & 0.2 & 0.3 & 0.4 & 0.5 & 0.6 & 0.7 & 0.8 & 0.9 & 1\end{array}$

Figure S14. Droplet formation (I) and mass fraction of species ' $b$ ' (II) inside the microchannel with rectangular cross-section with $\mathrm{AR}=2$ for WF corresponds to (a) 0.1 ; (b) 0.3 ; (c) 0.5 ; and (d) 0.7 . 